\title{
Screening for breast cancer in women with previous mantle radiotherapy for Hodgkin's disease
}

\author{
G. Ralleigh \\ Department of Radiology, King's College Hospital, Denmark Hill, London, UK.
}

\begin{abstract}
There is an established increased risk of secondary malignancy following radiation therapy for cancer in childhood or as a young adult. Breast cancer poses a particular problem as the population risk is significant and screening methods are available raising the question of possible screening interventions for women who are at high lifetime risk.
\end{abstract}

Keywords: Breast cancer; Hodgkin's disease; Screening; Supradiaphragmatic irradiation

\section{Breast cancer in women treated for Hodgkin's disease}

Relative risk and age at irradiation

Long-term follow-up of Hodgkin's disease (HD) survivors has revealed an increased incidence of secondary malignancy. More specifically, the relative risk of breast cancer after supradiaphragmatic irradiation (SDI) for HD is significantly increased [1-15], predominantly in those under the age of 30 years at the time of irradiation. Studies have shown a relative risk of 15-25 with greater risks for those treated between the ages of 10 and 16 years $[1,4,9,10]$. For women aged over 30 years at the time of treatment the relative risk is less significant, some studies have shown no excess risk while others have shown a relative risk of 2.4-3.7 [4,5,9,12]. Caution must be exercised in interpreting studies with incomplete follow-up as these may overestimate apparent risk (incomplete data is more likely to relate to subjects who have not had a second malignancy).

Correspondence to: Dr Gita Ralleigh, Department of Radiology, King's College Hospital, Denmark Hill, London, SE5 9RS, UK. E-mail: Gita.Ralleigh@kingsch.nhs.uk; Tel: +44 207346 3875; Fax: + 442073464363

Received 13/05/05

Accepted 07/06/05

First published online 11/11/05

BCO/344/2005/FO

\section{Latency}

The median induction period for breast cancer following SDI for HD in adults is long, around 15 years (range 4-20) [1,3,5,7-10,13]. However, this may be shorter in those patients treated in childhood. There is sparse follow-up data beyond 20 years, but Dores et al. [2] have followed a cohort of patients for greater than 25 years and shown a significant continuing risk of breast cancer.

\section{Radiation dose and chemotherapy}

Radiation dose and the radiation field significantly influence risk, with most cases of breast cancer following mantle radiotherapy, which includes the neck, supraclavicular fossae, axillae and mediastinum, and increased risk with high-dose regimes $[11,15,16]$. Chemotherapy may modify the radiotherapy-induced risk due to the hormonal consequences of ovarian toxicity.

\section{Characteristics of breast cancer developing after irradiation for HD}

\section{Histopathology}

Breast cancers developing after SDI for HD are biologically and pathologically similar to sporadic breast cancer [7,17-21]. Cutuli et al. found in a retrospective 
analysis of 133 breast cancers that 108 were invasive ductal carcinomas, 15 were ductal carcinoma in situ (DCIS) and 4 were lobular carcinoma with 6 other subtypes [20].

\section{Location of tumours and bilaterality}

Breast cancers developing after irradiation for HD differ from those observed sporadically in that tumours are more commonly bilateral [7,17-21] (9-29\% synchronous and metachronous) and are more likely to be located in the medial part of the breast [7].

\section{Minimising the risk of disease development}

Breast cancer is a common disease and therefore an increase in relative risk raises the issue of counselling patients of their increased risk and possible benefits of screening and prevention strategies.

Published results from large randomised-controlled trials testing tamoxifen for chemoprevention in women at high risk of developing breast cancer have shown a risk reduction of $38 \%$. This may have implications for the management of women following irradiation for HD [22].

\section{Possible surveillance strategies}

In the absence of conclusive data and the lack of randomised-controlled trials of possible screening methods in these women, a pragmatic approach is to consider the available options of self-examination, clinical examination, mammography, ultrasound and magnetic resonance imaging (MRI).

\section{Self-examination/clinical examination}

Randomised-controlled trials have shown that breast self-examination or clinical breast examination by a trained health professional has relatively low sensitivity (around 50-60\%) both in population screening and in high-risk groups [23,24]. More importantly no demonstrable mortality benefit has been shown.

\section{Mammography}

The mortality benefits of mammography for population screening over the age of 50 years (of the order of $25 \%$ in women who take up screening) have been long established [25-28]. There is some mortality benefit in women aged 40-49 years [29-31]. There is however insufficient evidence of the effectiveness of mammography for either population or high-risk screening of women under age 40 years. Mammography generally demonstrates reduced sensitivity in young women partly due to increased breast density. Post SDI breast cancers are generally visible on mammography (in $87-100 \%$ of cases) [18-21]. The high sensitivity in such a young population is due to the high prevalence of microcalcification (62-72\%) in those with abnormal mammograms [19,21].

Mammography screening may therefore be of benefit to these women but is unproven.

Furthermore mammography involves the use of ionising radiation with a consequent risk of cancer induction, which is higher in younger women. Women who have had SDI may understandably resist the use of further X-rays to detect a possible radiationinduced cancer.

Assuming a $15 \%$ risk of SDI-induced breast cancer (and that breast cancers developing are detectable with mammography), for a 30-year-old woman with average size breasts having yearly mammograms until age 50 years, the calculated potential benefit exceeds the risk of cancer induction by a factor of 100 (Faulkner K, personal communication).

\section{Ultrasound}

Bilateral whole-breast ultrasound can be used as an adjunct to mammographic screening in women with radiographically dense breasts. The quality of breast ultrasound has undoubtedly improved in the last 20 years with a consequent reduction in the false positive biopsy rate from $7.5 \%$ to $2.4 \%$ with an added cancer detection rate of approximately $0.3 \%$ in population screening [24,32-34]. At present European Consensus guidelines do not recommend breast ultrasound as a primary screening technique because of the high false negative and positive rates [35]. The problems of high operator dependence, difficulty covering the whole breast and low sensitivity for microcalcifications and thus DCIS, have also curtailed use of ultrasound for screening. The advantages of breast ultrasound are that it is widely available at a relatively low cost and does not use ionising radiation. It may have a role as an adjunct to other techniques or where other methods are contraindicated rather than as a primary screening test.

\section{$M R I$}

MRI has a high sensitivity for the early detection of breast cancer in young women at genetic risk particularly when performed with optimum technique and reported by radiologists experienced in interpretation [36,37]. A prospective multicentre cohort study of 649 women with a strong family history or who were either carriers of a BRCA1, BRCA2 or TP53 genetic mutation or a first degree relative of a carrier were examined with mammography and MRI. The sensitivity of MRI was $77 \%$ compared to $40 \%$ for mammography and $94 \%$ when both methods were used. However MRI has a reduced sensitivity for DCIS $(60-88 \%)$ compared to mammography $[38,39]$. 
Table 1. Surveillance for women at risk of breast cancer after treatment for HD with supradiaphragmatic irradiation.

\begin{tabular}{|c|c|c|}
\hline Age (years) & \multicolumn{2}{|l|}{ Recommended surveillance } \\
\hline$<25$ & \multicolumn{2}{|l|}{ No imaging } \\
\hline 25-29 & \multicolumn{2}{|c|}{ Annual MRI but if contraindications annual ultrasound (mammography is not recommended for this age group) } \\
\hline \multirow[t]{4}{*}{$30-50$} & \multicolumn{2}{|c|}{ Baseline two-view mammogram. Women should then be divided into two groups: } \\
\hline & \multirow{3}{*}{$\begin{array}{l}\text { Predominantly fatty breast tissue } \\
\text { Annual two-view mammography }\end{array}$} & Dense breast tissue \\
\hline & & $\begin{array}{l}\text { Annual two-view mammography plus MRI: Unless there are } \\
\text { contraindications when the patient should be offered }\end{array}$ \\
\hline & & $\begin{array}{l}\text { Annual mammography plus ultrasound: If breast tissue } \\
\text { becomes predominantly fatty prior to the age of } 50 \text { years } \\
\text { the patient should move into group } 1 \text { (i.e. annual } \\
\text { mammography only) }\end{array}$ \\
\hline$>50$ & \multicolumn{2}{|c|}{ Three-yearly mammography should be offered within the NHS Breast Screening Programme (NHSBSP) } \\
\hline
\end{tabular}

The specificity of MRI is variable $[40,41]$, benign masses and normal breast parenchyma may enhance in young women leading to false positives (a problem compounded by the difficulties of MR-guided biopsy). The pathology of breast cancer in women at genetic risk is different from sporadic breast cancer, which may influence the choice of screening method [42], but this is not the case for SDI-induced breast cancer [43].

$\mathrm{MRI}$ is also significantly more expensive than mammography or ultrasound, less available and is not tolerated by some patients.

\section{Screening age and interval}

The average age of breast cancer presentation in women post SDI is around 40 years but may be younger for those treated in childhood. Any method of screening should therefore begin at a younger age than population screening for sporadic breast cancer. For those treated under the age of 17 years screening from age of 25 years is appropriate, for those treated between 17 and 35 years screening should begin 8 years after the completion of treatment for HD.

Breast cancer in younger women has a shorter sojourn time (1-2 years aged $40-49$ vs. 3 years in over 50s) $[44,45]$ and annual screening is therefore advised.

\section{Conclusion}

Women treated with SDI for HD under age 35 years are at increased risk of subsequent breast cancer. No screening method is of proven efficacy in these women.

Screening causes adverse effects; anxiety and costs are associated with false-positive diagnosis and false reassurance. There is a balance between the potential benefit of mortality reduction and the risks, and the magnitude of both is unclear. Women should be counselled to allow an informed decision about surveillance and alternative risk reduction strategies such as surgery or chemoprevention. For those who opt for surveillance a recommended schedule has been developed by expert consensus from available evidence (Table 1).

Centres organising such surveillance for women with previous SDI for HD should record screening methods and outcomes. Only evaluation of such screening activity will allow future calculation of risks and benefits.

\section{Acknowledgements}

Dr Rosalind Given-Wilson and other members of the RCR Breast Group Working Party on HD and Secondary Breast Cancer: Robin Wilson, Andy Evans, Ruth Given-Wilson, Peter Britton, and Keith Faulkner are acknowledged.

\section{References}

1. Bhatia S, Robison LL, Oberlin O, et al. Breast cancer and other second neoplasms after childhood Hodgkin's disease. N Engl J Med 1996; 334: 745-751.

2. Dores GM, Metayer C, Curtis RE, et al. Second malignant neoplasms among long-term survivors of Hodgkin's disease: a population-based evaluation over 25 years. J Clin Oncol 2002; 20: 3484-3494.

3. Metayer C, Lynch CF, Clarke EA, et al. Second cancers among long-term survivors of Hodgkin's disease diagnosed in childhood and adolescence. J Clin Oncol 2000; 18: 2435-2443.

4. Swerdlow AJ, Barber JA, Hudson GV, et al. Risk of second malignancy after Hodgkin's disease in a collaborative British cohort: the relation to age at treatment. J Clin Oncol 2000; 18: 498-509.

5. van Leeuwen FE, Klokman WJ, Veer MB, et al. Longterm risk of second malignancy in survivors of Hodgkin's disease treated during adolescence or young adulthood. J Clin Oncol 2000; 18: 487-497.

6. Clemons M, Loijens L, Goss P. Breast cancer risk following irradiation for Hodgkin's disease. Cancer Treat Rev 2000; 26: 291-302. 
7. Yahalom J, Petrek JA, Biddinger PW, et al. Breast cancer in patients irradiated for Hodgkin's disease: a clinical and pathologic analysis of 45 events in 37 patients. $J$ Clin Oncol 1992; 10: 1674-1681.

8. Mauch PM, Kalish LA, Marcus KC, et al. Second malignancies after treatment for laparotomy staged IA-IIIB Hodgkin's disease: long-term analysis of risk factors and outcome. Blood 1996; 87: 3625-3632.

9. Aisenberg AC, Finkelstein DM, Doppke KP, et al. High risk of breast carcinoma after irradiation of young women with Hodgkin's disease. Cancer 1997; 79: 1203-1210.

10. Hancock SL, Tucker MA, Hoppe RT. Breast cancer after treatment of Hodgkin's disease. J Natl Cancer Inst 1993; 85: 25-31.

11. Travis LB, Hill DA, Dores GM, et al. Breast cancer following radiotherapy and chemotherapy among young women with Hodgkin disease. J Am Med Assoc 2003; 290: 465-475.

12. $\mathrm{Ng} \mathrm{AK}$, Bernardo MP, Weller E, et al. Long-term survival and competing causes of death in patients with earlystage Hodgkin's disease treated at age 50 or younger. $J$ Clin Oncol 2002; 20: 2101-2108.

13. Foss Abrahamsen A, Andersen A, Nome O, et al. Longterm risk of second malignancy after treatment of Hodgkin's disease: the influence of treatment, age and follow-up time. Ann Oncol 2002; 13: 1786-1791.

14. Tucker MA, Coleman CN, Cox RS, et al. Risk of second cancers after treatment for Hodgkin's disease. $N$ Engl $J$ Med 1988; 318: 76-81.

15. Guibout C, Adjadj E, Rubino C, et al. Malignant breast tumours after radiotherapy for a first cancer during childhood. J Clin Oncol 2005; 23: 197-204.

16. van Leeuwen FE, Klokman WJ, Stovall M, et al. Roles of radiation dose, chemotherapy, and hormonal factors in breast cancer following Hodgkin's disease. J Natl Cancer Inst 2003; 95: 971-980.

17. Wolden SL, Hancock SL, Carlson RW, et al. Management of breast cancer after Hodgkin's disease. J Clin Oncol 2000; 18: 765-772.

18. Diller L, Nancarrow CM, Shaffer K, et al. Breast cancer screening in women previously treated for Hodgkin's disease: a prospective cohort study. J Clin Oncol 2002; 20: 2085-2091.

19. Dershaw DD, Yahalom J, Petrek JA. Breast carcinoma in women previously treated for Hodgkin disease: mammographic evaluation. Radiology 1992; 184: 421-423.

20. Cutuli B, Borel C, Dhermain F. Breast cancer occurred after treatment for Hodgkin's disease: analysis of 133 cases. Radiother Oncol 2001; 59: 247-255.

21. Tardivon AA, Garnier ML, Beaudre A, Girinsky T. Breast carcinoma in women previously treated for Hodgkin's disease: clinical and mammographic findings. Eur Radiol 2003; 9: 1666-1671.

22. Cuzick J, Forbes J, Edwards R, et al., IBIS Investigators. First results from the International Breast Cancer Intervention Study (IBIS-1): a randomised prevention trial. Lancet 2002; 360: 817-824.

23. Bobo JK, Lee NC, Thames SF. Findings from 752081 clinical breast examinations reported to a national screening program from 1995 through 1998. J Natl Cancer Inst 2000; 92: 971-976.

24. Kolb TM, Lichy J, Newhouse JH. Comparison of the performance of screening mammography, physical examination, and breast US and evaluation of factors that influence them: an analysis of 27,825 patient evaluations. Radiology 2002; 225: 165-175.

25. Tabar L, Fagerberg C, Chen $\mathrm{HH}$, et al. Efficacy of breast cancer screening by age: new results from the Swedish Two-County Trial. Cancer 1995; 75: 2507-2517.

26. Tabar L, Fagerberg C, Gad A, et al. Reduction in mortality from breast cancer after mass screening with mammography: randomised trial from the Breast Cancer Screening Working Group of the Swedish National Board of Health and Welfare. Lancet 1985; 1: 829-832.

27. Kerlikowske K, Grady D, Rubin SM, et al. Efficacy of screening mammography: a meta-analysis. J Am Med Assoc 1995; 273: 149-154.

28. International Agency for Research on Cancer. Handbooks on Cancer Prevention. Vol 7: Breast Cancer Screening. IARC, 2002.

29. Kerlikowske K. Efficacy of screening mammography among women aged 40 to 49 years and 50 to 69 years: comparison of relative and absolute benefit. J Nat/ Cancer Inst Monogr 1997; 22: 79-86.

30. Hendrick RE, Smith RA, Rutledge III JH, Smart CR. Benefit of screening mammography in women aged 40-49: a new meta-analysis of randomised controlled trials. I Natl Cancer Inst Monogr 1997; 22: 87-92.

31. Bjurstam N, Bjorneld L, Duffy SW, et al. The Gothenburg breast screening trial: first results on mortality, incidence and mode of detection for women ages 39-49 years at randomisation. Cancer 1997; 80: 2091-2099.

32. Crystal P, Strano SD, Shcharynski S, Koretz MJ. Using sonography to screen women with mammographically dense breasts. Am J Roentgenol 2003; 181: 177-182.

33. Kaplan SS. Clinical utility of bilateral whole-breast US in the evaluation of women with dense breast tissue. Radiology 2001; 221: 641-649.

34. Buchberger W, Niehoff A, Obrist P. Clinically and mammographically occult breast lesions: detection and classification with high resolution sonography. Sem Ultrasound CT MR 2000; 21: 325-336.

35. Teh W, Wilson ARM. The role of ultrasound in breast cancer screening. A consensus statement by the European Group for breast cancer screening. Eur J Cancer 1998; 34: 449-450.

36. Kuhl CK, Schmutzler RK, Leutner CC, et al. Breast MR imaging screening in 192 women proved or suspected to be carriers of a breast cancer susceptibility gene: preliminary results. Radiology 2000; 215: 267-279.

37. Warner E, Plewes DB, Shumak RS, et al. Comparison of breast magnetic resonance imaging, mammography, and ultrasound for surveillance of women at high risk for hereditary breast cancer. J Clin Oncol 2001; 19: 3524-3531.

38. Orel SG, Mendonca MH, Reynolds C, et al. MR imaging of ductal carcinoma in situ. Radiology 1997; 202: 413-420.

39. Neubauer H, Li M, Kuehne-Heid R, et al. High grade and non-high grade ductal carcinoma in situ on dynamic MR mammography: characteristic findings for signal increase and morphological pattern of enhancement. Br J Radiol 2003; 76: 3-12.

40. MARIBS study group. Screening with magnetic resonance imaging and mammography of a UK population at high family risk of breast cancer: a prospective multicentre cohort study (MARIBS). Lancet 2005; 365: 1769-1778.

41. Stoutjesdijk MJ, Boetes C, Jager GJ, et al. Magnetic resonance imaging and mammography in women with a 
hereditary risk of breast cancer. J Natl Cancer Inst 2001; 93: 1095-1102.

42. Breast Cancer and Linkage Consortium. Pathology of familial breast cancer: differences between breast cancers in carriers of BRCA1 or BRCA2 mutations and sporadic breast cancers. Lancet 1997; 349: 1505-1510.

43. Nichols KE, Heath JA, Friedman D, et al. TP53, BRCA1, and BRCA2 tumor suppressor genes are not commonly mutated in survivors of Hodgkin's disease with second primary neoplasms. J Clin Oncol 2003; 21: 4505-4509.

44. Henderson IC, Patek AJ. Are breast cancers in young women qualitatively distinct? Lancet 1997; 349: 1488-1489.

45. Walker RA, Lees E, Webb MB, Dearing SJ. Breast carcinomas occurring in young women $(<35$ years) are different. Br J Cancer 1996; 74: 1796-1800. 